
https://doi.org/10.30534/ijeter/2020/50822020

\title{
Interpolating single-beam data for sea bottom GIS modelling
}

\author{
Emanuele Alcaras ${ }^{1}$, Luigi Carnevale ${ }^{2}$, Claudio Parente ${ }^{3}$ \\ ${ }^{1}$ Università di Napoli “Parthenope”, Italy, emanuele.alcacaras@uniparthenope.it \\ ${ }^{2}$ Marina Militare Italiana, Italy, luigi.carnevale@ marina.difesa.it \\ ${ }^{3}$ Università di Napoli “Parthenope", Italy, claudio.parente@ uniparthenope.it
}

\begin{abstract}
The "Istituto Idrografico della Marina Militare" (IIMM) secures the Italian hydrographic service through the execution of bathymetric surveys, the production of nautical charts and publications, and the dissemination of nautical information, aimed at the safety of navigation and of human life at sea. The datasets of depth points acquired with bathymetric surveys are useful to model sea-bottom starting from the interpolation methods available in Geographic Information System (GIS) software. In this paper, a single-beam dataset from IIMM is used with the aim to compare different interpolation methods for sea bottom GIS modelling. The study area is the sea close to the east coast of Isola del Giglio in Tuscan Archipelago (Italy). The following nine different interpolation methods are selected and applied using ArcGIS software, version 10.3.1: Inverse Distance Weighting (IDW), Local Polynomial Interpolations of different orders (from the first to the fifth order), Ordinary Kriging, with three different Variogram models (Gaussian, circular, exponential). The result accuracy is tested via cross-validation leave-one-out, so statistical values (minimum, maximum, mean and root mean square error) are calculated for each interpolation method, taking into account the residual given for each sampling point between measured and interpolated value. Finally, a 3D model is created from the best interpolating algorithm. The results remark the role of the cross validation as preliminary way to select the most preforming interpolation method that is difficult to identify in other way.
\end{abstract}

Key words : Single-beam, Interpolation, GIS Modelling, Bathymetry.

\section{INTRODUCTION}

When dealing with geophysical sciences, it is essential to introduce spatial interpolation, which can be defined as the estimation of the variables at undetected locations in geographic space based on the values at observed locations [1]. Spatial interpolations can be classified in accordance with their basic hypotheses and mathematical natures in two categories: deterministic and geostatistical methods [2, 3]. Deterministic interpolation techniques apply mathematical functions to find the values at unknown locations based on relation to nearby data points [4]. Geostatistical methods, based on the theory of regionalized variables [5], are probabilistic statistical methods that allow to take advantage of the spatial correlation between neighboring observations to predict attribute values at unsampled locations [6].

In the case of geostatistical modeling, the uncertainty of the interpolation result can be modeled with a much higher level of detail [7], as reported from several authors [8, 9, 10].

Spatial interpolation is a concept strongly related to the digital terrain model (DTM), introduced by Miller \& Laflamme [11], or more generally to the digital elevation model (DEM). DEM can be defined as the digital representation of the land surface elevation with respect to any reference datum [12]. Many techniques permit to acquire data for DEM, such as land survey [13], LIDAR [14], photogrammetry [15], UAV surveys [16], etc.

Interpolation techniques that permit to generate different kinds of DEM, can be also used for seabed models: this can be indicated as Digital Depth Model (DDM) since it describes the variability of the distance between the sea surface and sea bed [17]. As a matter of facts, according to the International Hydrographic Organization (IHO), interpolation techniques permit to obtain a bathymetric model which can be defined as "a digital representation of the topography (bathymetry) of the seafloor by coordinates and depths" [18]. Bathymetric data can be achieved with different techniques, from optical satellite sensors [19], nautical maps [20], multi-beam echo-sounders [21], etc.

The aim of this article is to compare different interpolation methods from a single-beam dataset evaluating their accuracy. The most performing model is then used to acquire a $3 \mathrm{D}$ view of the sea floor. All the operations are carried out in ArcGIS version 10.3.1 using the extension Geostatistical Analyst. The paper is structured as follows. In the next section, we present the study area and the dataset. In section 3, we examine nine interpolation methods, resuming their principal characteristics: Inverse Distance Weighting (IDW), Local Polynomial Interpolations of different orders (from the first to the fifth order), Ordinary Kriging, with three different Variogram models (Gaussian, circular, exponential); in addition, we define the methodological approach to assess the accuracy provided by their application. In section 4, we analyze and discuss the results obtained with the application of the considered methods. Finally, we conclude the paper in section 5, remarking the highlights of the study and delineating future developments. 


\section{STUDY AREA AND DATASET}

\subsection{Study area}

Isola del Giglio is an Italian island, the second largest in the Tuscan Archipelago, lying within the Arcipelago Toscano National Park, situated in the Tyrrhenian Sea (Figure 1).

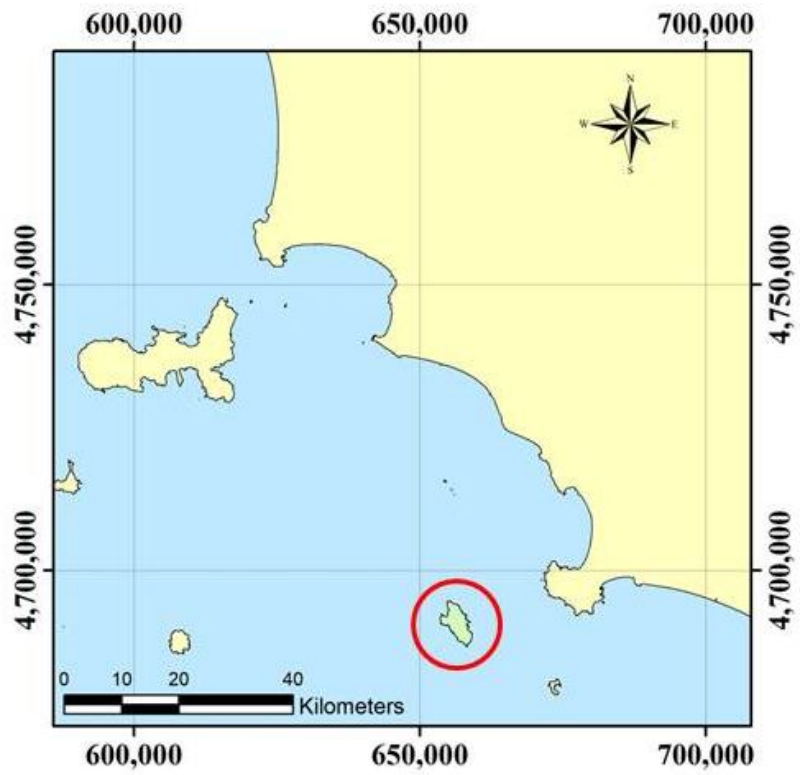

Figure 1: Isola del Giglio collocation in Tuscan Archipelago.

The island has an area of $21.2 \mathrm{Km}^{2}$, the coastline has an approximate extension of $27 \mathrm{Km}$ and is located $15 \mathrm{Km}$ off the promontory of Monte Argentario [22]. Mainly mountainous, it consists almost completely of granite, crowning in the Poggio della Pagana, which has an elevation of 496 meters [23]. Its coasts are predominantly high and rocky with numerous small bays and inlets.

The study area is located off the coast of the town of Giglio Porto, which is characterized by a steep rocky slope that drops quickly to a $100 \mathrm{~m}$ depth at a distance of about $350 \mathrm{~m}$ from the coast [24].

An aerial view of the island is shown in Figure 2.

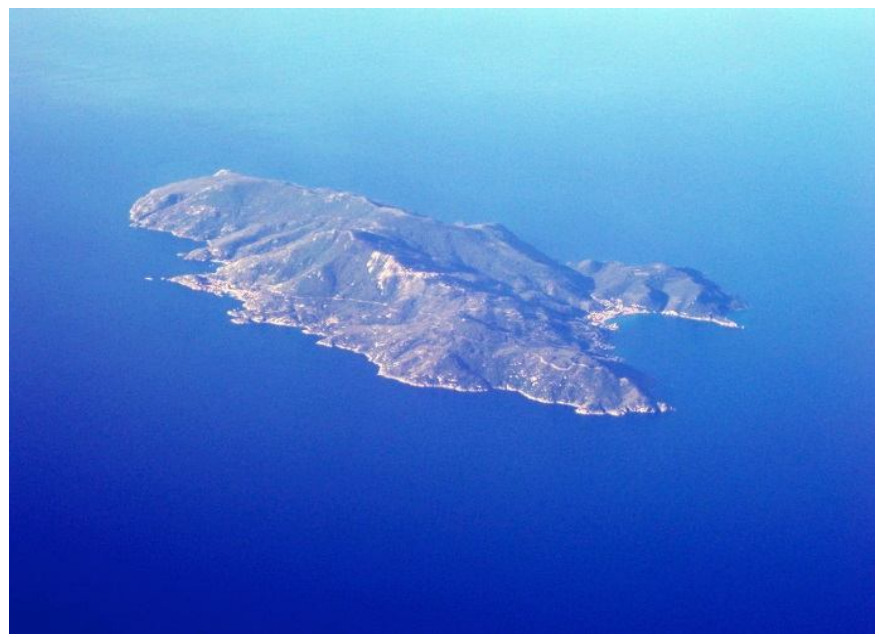

Figure 2: Aerial view of Isola del Giglio.
The considered study area concerns the sea floor inside and neighboring the gulf known as "Cala delle Cannelle", between "Punta dello Smeraldo" and "Punta di Capo Marino" in the east side of the island (Figure 3).

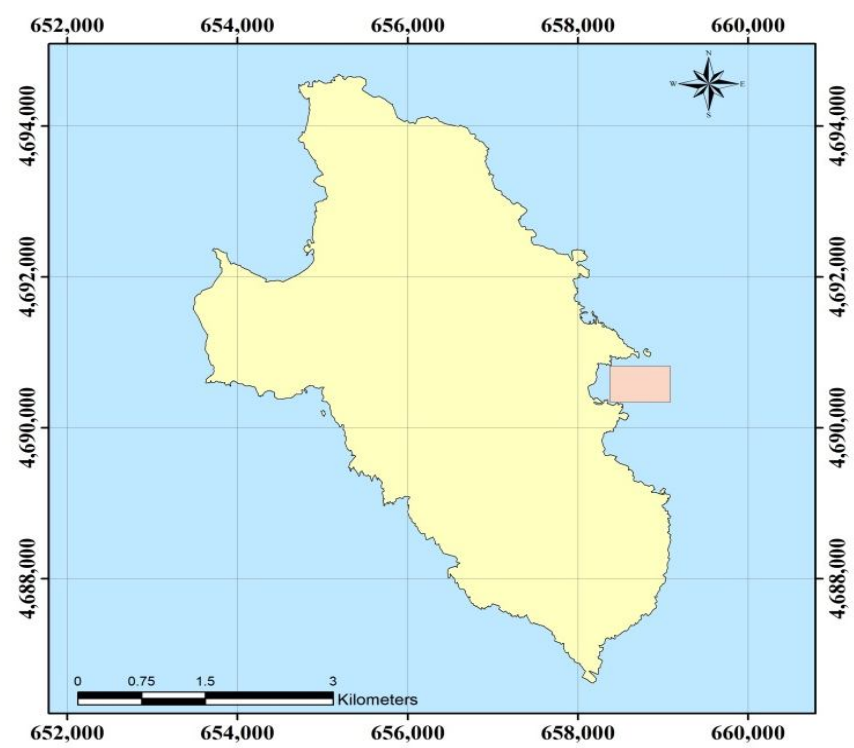

Figure 3: The study area (in orange).

The area has an extension of about $0.34 \mathrm{Km}^{2}(714 \mathrm{~m} \times 478$ $\mathrm{m})$. Its conformation resembles a bowl, becoming deeper moving away from the shoreline. The shallower area has a minimum depth of 4.5 meters, is really close to the coast, while the deepest point has a depth of 98 meters.

\subsection{Dataset}

The dataset for this work was provided by "Istituto Idrografico della Marina Militare" (IIMM), acquired during a survey off the coasts of Giglio Island. The acquisition was carried out with single-beam technology. It comprises a total of 1609 points with a depth precision of $10 \mathrm{~cm}$ and refers to a cartographic scale of 1:2000 defined in a UTM/WGS84 representation system. From the starting dataset 883 points are chosen: the ones located in the central area of the survey and sampled as regularly as possible (Figure 4).

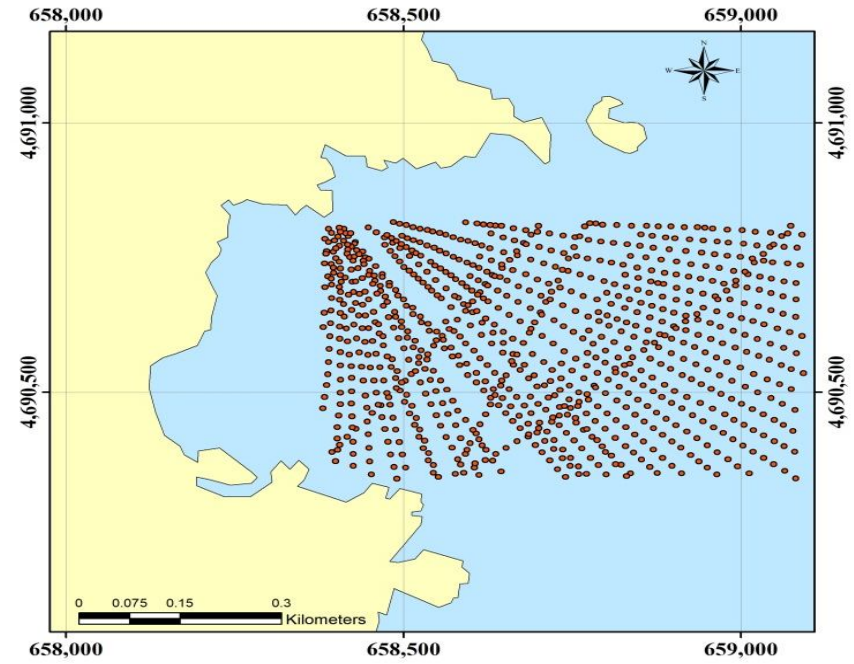

Figure 4: The selected 883 points of the starting dataset. 


\section{METHODS}

\subsection{Interpolation methods}

The selected dataset is interpolated by the use of the following models:

- Inverse Distance Weighting (IDW);

- Local Polynomial Interpolation of the First Order (LPI-1);

- Local Polynomial Interpolation of the Second Order (LPI-2);

- Local Polynomial Interpolation of the Third Order (LPI-3);

- Local Polynomial Interpolation of the Fourth Order (LPI-4);

- Local Polynomial Interpolation of the Fifth Order (LPI-5);

- Ordinary Kriging with Gaussian model (OK-G);

- Ordinary Kriging with circular model (OK-C);

- Ordinary Kriging with exponential model (OK-E).

IDW is one of the most commonly used methods for surface modelling. It is based on the intuitive concept that the closest known values must carry more weight in determining the interpolated value for any unmeasured location [25].

Local polynomial interpolation (LPI) uses a selected sample of known points from the entire dataset and a polynomial equation to estimate unknown values. In other terms, it permit to fit many polynomials, each within specified overlapping neighborhoods [26]. It is similar to Global Polynomial Interpolation, except that it does not use the entire dataset, but only a part of them included in a window that is shifted across the map area [27]. A minimum number of points is required in reference to the order of the polynomial: three points for a first order polynomial, six points for a second order, ten points for a third order, etc. [28]. In the case of big data, that, as is well known, are characterized by a huge volume [29, 30], polynomial interpolation would represent the data succinctly [31].

Similarly to IDW, the Kriging interpolation weights the neighboring measured values to develop a prediction for an unmeasured location [32]. However, in Kriging the weights are built on the total spatial arrangement of the measured points too [33]. In fact, Kriging assumes that spatial correlation can be used to describe the variation in the surface, that is a reflection of the distance or direction between sample points [34]. The semi-variogram model is used to best fit the empirical semi-variogram that plots the variance of the difference between field depth values at two locations against the distance [17]. Among the semi-variogram models available in literature, three of them are considered in this study: Gaussian Model, circular model, exponential model.

The applications of all considered methods are carried out in Geostatistical Analyst, extension powered by ArcGIS [35]. Particularly, a specified number of points, or all points within a specified radius, are used to determine the output value of each location. Fixing the value of this radius, the number of the neighbors is defined. In addition, the neighborhood can be divided into sectors to include values from all directions [36]. Four sectors (with offset $=45^{\circ}$ ) are introduced when required. Other parameters, such as maximum and minimum number of neighbors, are set with specific values in every case to optimize the results.

\subsection{Accuracy evaluation}

To evaluate the accuracy of the interpolated models, cross-validation, a statistical validation technique for assessing the interpolation model performance [37], is used. Different approaches are typically adopted for cross validation. Leave-one-out method omits a point and calculates the value at this location using the remaining points. The procedure is repeated for a second point, and so on. The difference between the predicted and actual values at the location of the omitted point in turn (residual), is calculated for evaluating the goodness of the adopted interpolation method [38].

Root mean square error (RMSE), that is just the square root of MSE [39], is the best indicator to evaluate the interpolation method performance. It is given by the following formula:

$$
R M S E=\sqrt{\frac{\sum_{i=1}^{N}\left(z_{i}(x, y)-z_{i}^{\prime}(x, y)\right)^{2}}{N}}
$$

Where:

- $\quad \mathrm{N}$ is the number of the depth points;

- $z_{i}(x, y)$ is the measured depth at the location $\mathrm{i}(\mathrm{x}, \mathrm{y})$;

- $\mathrm{z}_{i}^{\prime}(\mathrm{x}, \mathrm{y})$ is the estimated depth at the same location $\mathrm{i}(\mathrm{x}, \mathrm{y})$.

\section{RESULTS AND DISCUSSION}

The results of interpolations computed by Geostatistical Analyst are 2D models. Finally, nine 2D bathymetric models are obtained in this study and reported below (Figures 5 to 13).

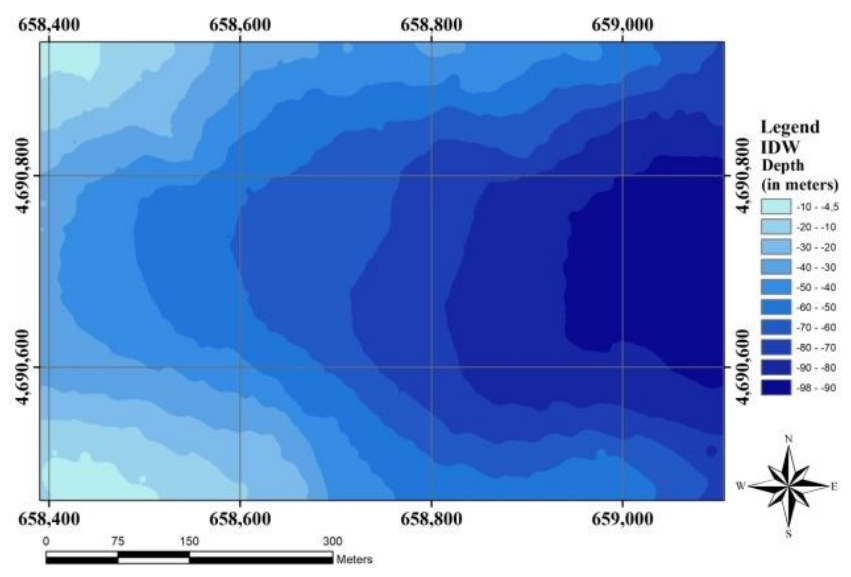

Figure 5: 2D bathymetric model resulting from Inverse Distance Weighting interpolation. 


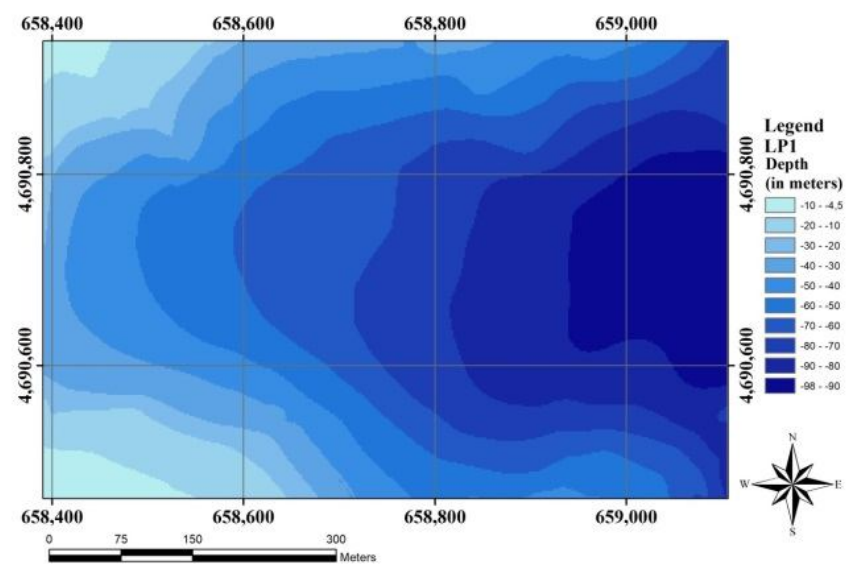

Figure 6: $2 \mathrm{D}$ bathymetric model resulting from Local Polynomial Interpolation of the First Order.

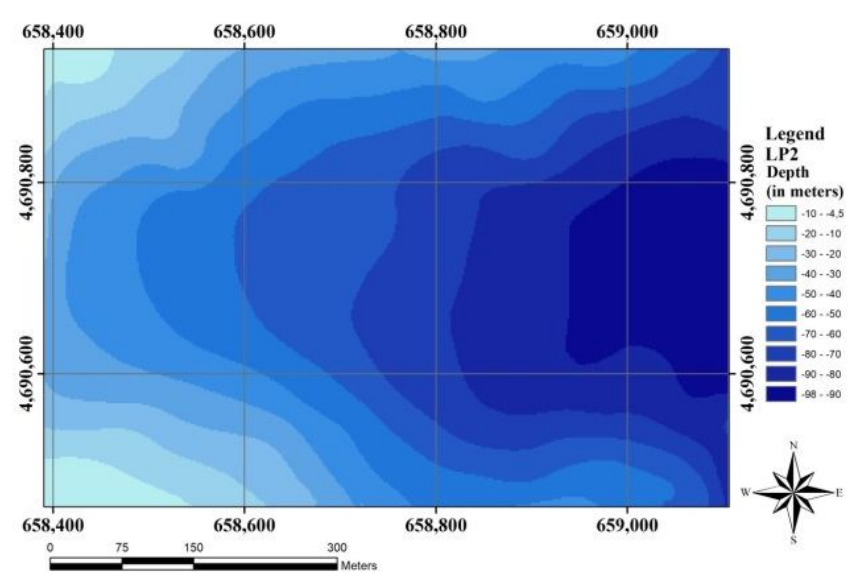

Figure 7: 2D bathymetric model resulting from Local Polynomial Interpolation of the Second Order.

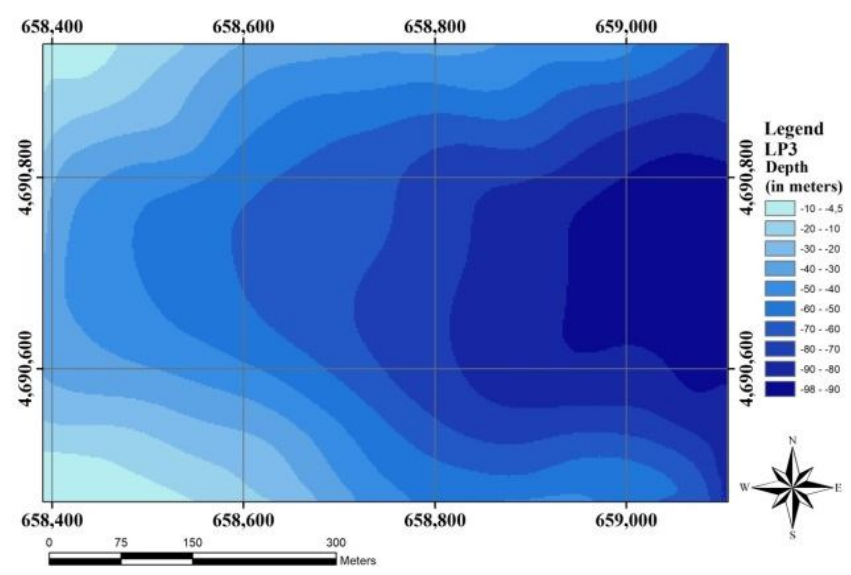

Figure 8: Figure 8 - 2D bathymetric model resulting from Local Polynomial Interpolation of the Third Order.

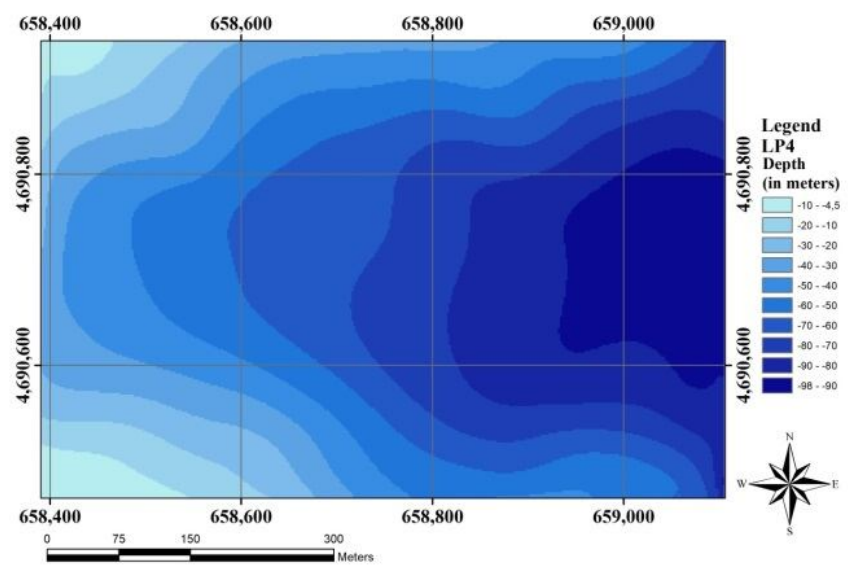

Figure 9: 2D bathymetric model resulting from Local Polynomial Interpolation of the Fourth Order.

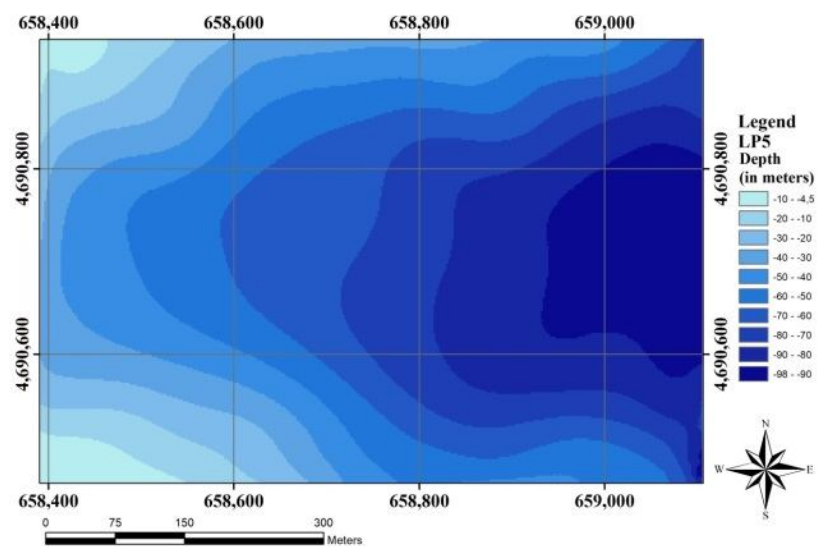

Figure 10: 2D bathymetric model resulting from Local Polynomial Interpolation of the Fifth Order.

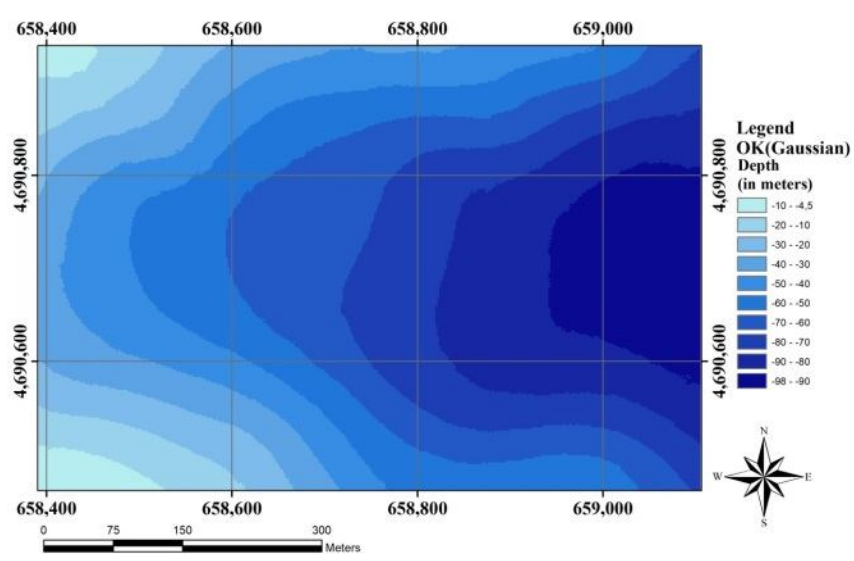

Figure 11: 2D bathymetric model resulting from Ordinary Kriging (Gaussian Model) Interpolation. 


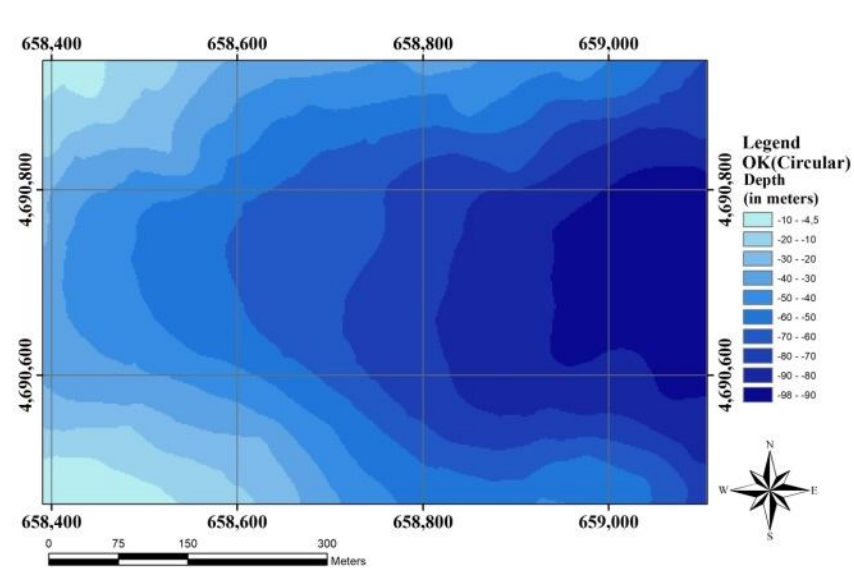

Figure 12: $2 \mathrm{D}$ bathymetric model resulting from Ordinary Kriging (Circular Model) Interpolation.

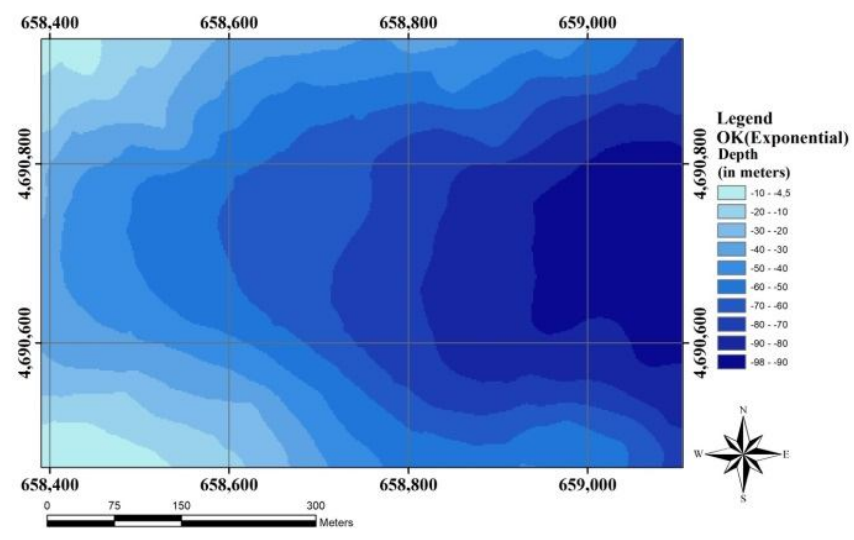

Figure 13: 2D bathymetric model resulting from Ordinary Kriging (Exponential Model) Interpolation.

For each interpolation method, the following statistic values calculated for the residuals generated by the cross-validation approach are considered: mean, minimum (Min), maximum (Max), standard deviation (St. Dev.), root mean square error (RMSE). Those values are reported in Table 1.

Table 1: Statistical values of residuals resulting from cross validation

\begin{tabular}{|c|c|c|c|c|c|}
\hline $\begin{array}{c}\text { Interpolati } \\
\text { on method }\end{array}$ & $\begin{array}{c}\text { Min } \\
(\mathbf{m})\end{array}$ & $\begin{array}{c}\text { Max } \\
(\mathbf{m})\end{array}$ & $\begin{array}{c}\text { Mean } \\
(\mathbf{m})\end{array}$ & $\begin{array}{c}\text { St. } \\
\text { Dev. } \\
(\mathbf{m})\end{array}$ & $\begin{array}{c}\text { RMSE } \\
(\mathbf{m})\end{array}$ \\
\hline IDW & -9.400 & 6.052 & -0.123 & 1.772 & 1.776 \\
\hline LPI-1 & -7.093 & 6.208 & 0.139 & 1.889 & 1.894 \\
\hline LPI-2 & -7.448 & 5.959 & -0.003 & 1.186 & 1.186 \\
\hline LPI-3 & -7.076 & 6.586 & 0.022 & 1.310 & 1.310 \\
\hline LPI-4 & -6.985 & 7.637 & -0.004 & 1.321 & 1.321 \\
\hline
\end{tabular}

\begin{tabular}{|c|c|c|c|c|c|}
\hline LPI-5 & -7.554 & 22.874 & 0.025 & 1.549 & 1.549 \\
\hline OK-G & -7.592 & 7.782 & 0.235 & 1.667 & 1.683 \\
\hline OK-C & -6.785 & 6.356 & 0.006 & 1.215 & 1.215 \\
\hline OK-E & -6.784 & 6.155 & 0.002 & 1.219 & 1.219 \\
\hline
\end{tabular}

The results of the elaborations permit to understand which method better fits this single-beam dataset. Particularly, the range of minimum values goes from $-9.400 \mathrm{~m}$ obtained for IDW, to $-6.784 \mathrm{~m}$ resulting from OK-E. The range of maximum values goes from $5.959 \mathrm{~m}$ obtained for LPI-2, to $22.874 \mathrm{~m}$ resulting from LPI-5. The range of mean values goes from $-0.123 \mathrm{~m}$ obtained for IDW, to $0.235 \mathrm{~m}$ resulting from OK-G. The range of RMSE goes from $1.186 \mathrm{~m}$ for LPI-2 to $1.776 \mathrm{~m}$ resulting from IDW.

By analyzing the RMSE values, LPI- 2 seems to be the most performing interpolation method. However, other algorithms seems to perform well too, e.g. OK-C and OK-E. Generally, kriging interpolators work better than polynomial interpolators, but different results can be achieved, such as in this case, because the particular morphology of the sea-bottom.

Because it presents the best accuracy level, the 3D model resulting from LPI-2 algorithm application is built in the ArcGIS tool named ArcScene [40], and reported in figure 14.

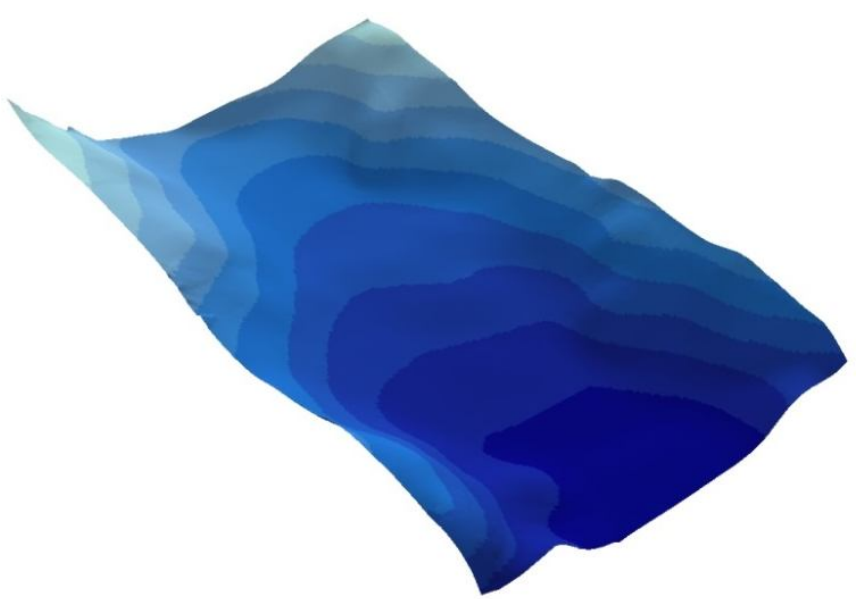

Figure 14: 3D representation of the seafloor using Local Polynomial Interpolation of the Second Order.

\section{CONCLUSION}

Interpolation algorithms available in GIS software allow to easily model sea bottom starting from single-beam data. The analysis of the specific situation to define a-priori the most suitable interpolation tool is difficult, so the comparison of the accuracy level obtained by the application of each algorithm is to prefer. In fact, cross validation implemented by leave-one-out method permits to select the most performing interpolation algorithm for accurate sea bottom model.

In this paper, the attention is focused on the interpolation techniques for a dataset acquired by IIMM using a 
single-beam echo-sounder, off the coast of Isola del Giglio, in the Tuscan Archipelago (Italy). Nine algorithms are applied to 883 depth points, contained in an area of about 0.34 square kilometers. As an outcome of the elaborations, LPI-2 model results the most adaptive to this specific dataset, probably due to the particular conformation of the investigated area. Ordinary Kriging gives also a good response, ratifying the great flexibility and adaptableness of kriging methodology to interpolate depth points that are not equally distributed.

However, this experiment remarks the limits of the IDW algorithm, and the limit given by the conformation of the area to other methods i.e. the Local Polynomial interpolation of the First Order.

Improvements for the future could be dedicated on the relationship among interpolation methods and sea bed morphology as well as on the relationship between point density and model accuracy.

\section{ACKNOWLEDGEMENT}

This work synthesizes results of experiments performed within a research project supported by University of Naples "Parthenope" and coordinated by Prof. Stefano Pierini to whom we express our very great appreciation. We would also like to thank the Italian Hydrographic Office (Istituto Idrografico della Marina Militare) in the persons of the Director Dr. Luigi Sinapi for authorizing the use of single beam data for scientific purpose, and the Hydrographic Surveyor Dr. Nunziante Langellotto for collecting and providing the data.

\section{REFERENCES}

1. E. Alcaras, C. Parente, and A. Vallario. Comparison of different interpolation methods for DEM production, International Journal of Advanced Trends in Computer Science and Engineering, vol. 6, no. 4, July - August 2019, pp. 1654-1659.

https://doi.org/10.30534/ijatcse/2019/91842019

2. X. Li, G. Cheng, and L. Lu. Comparison of spatial interpolation methods $[\mathrm{J}]$. Advance in Earth sciences, vol. 3, 2000.

3. D. Ozturk and F. Kilic. Geostatistical approach for spatial interpolation of meteorological data, Anais $d a$ Academia Brasileira de Ciências, Vol. 88, no. 4, 2016, pp. 2121-2136.

http://dx.doi.org/10.1590/0001-3765201620150103

4. J. Dinwoodie, S. Tuck, H. Knowles, J. Benhin, and M. Sansom. Sustainable development of maritime operations in ports, Business Strategy and the Environment, vol. 21, no. 2, 2012, pp. 111-126.

https://doi.org/10.1002/bse.718

5. A. G. Journel and C. J. Huijbregts. Mining geostatistics, Vol. 600, London: Academic press, 1978.

6. P. Goovaerts. Geostatistical approaches for incorporating elevation into the spatial interpolation of rainfall, Journal of hydrology, vol. 228, no. 1-2, 2000, pp. 113-129.

7. T. Hengl, B. Bajat, D. Blagojević, and H. I. Reuter. Geostatistical modeling of topography using auxiliary maps, Computers \& Geosciences, vol. 34, no. 12, 2008, pp. 1886-1899.

https://doi.org/10.1016/j.cageo.2008.01.005

8. G. Q. Tabios III and J. D. Salas. A comparative analysis of techniques for spatial interpolation of precipitation 1, JAWRA Journal of the American Water Resources Association, vol. 21, no. 3, 1985, pp. 365-380.

9. W. C. M. Van Beers and J. P. C. Kleijnen. Kriging for interpolation in random simulation, Journal of the Operational Research Society, vol. 54, no. 3, 2003, pp. 255-262.

10. A. Šiljeg, M, Barada, I. Marić, and V. Roland. The effect of user-defined parameters on DTM accuracy development of a hybrid model, Applied Geomatics, vol. 11, no. 1, 2019, pp. 81-96. https://doi.org/10.1007/s12518-018-0243-1

11. C. L. Miller and R. A. Laflamme, The digital terrain model theory and application, Photogrammetric Engineering, vol. 24, no. 3, 1958, pp. 433-442.

12. A. Balasubramanian. Digital elevation model (DEM) in GIS, Technical report, University of Mysore, 2017. https://doi.org/10.13140/rg.2.2.23976.47369

13. G. Petersen, J. V. Sutcliffe, and N. Fohrer. Morphological analysis of the Sudd region using land survey and remote sensing data, Earth Surface Processes and Landforms: The Journal of the British Geomorphological Research Group, vol. 33, no. 11, 2008, pp. 1709-1720.

https://doi.org/10.1002/esp.1643

14. X. Liu. Airborne LiDAR for DEM generation: some critical issues, Progress in physical geography, vol. 32, no. 1, 2008, pp. 31-49. https://doi.org/10.1177/0309133308089496

15. M. Fabris and A. Pesci. Automated DEM extraction in digital aerial photogrammetry: precisions and validation for mass movement monitoring, Annals of Geophysics, vol. 48, no. 6, 2005.

16. D. Ebolese. M. Lo Brutto, and G. Dardanelli. UAV survey for the archaeological map of Lilybaeum (Marsala, Italy), International Archives of the Photogrammetry, Remote Sensing \& Spatial Information Sciences, Volume XLII-2/W11, 2019.

https://doi.org/10.5194/isprs-archives-XLII-2-W11-4952019

17. C. Parente and A. Vallario. Interpolation of Single Beam Echo Sounder Data for 3D Bathymetric Model, International Journal of Advanced Computer Science and Applications, vol. 10, no. 10, 2019, pp. 6-13. https://doi.org/10.14569/IJACSA.2019.0101002

18. International Hydrographic Organization (IHO), IHO Standards for Hydrographic Surveys - 5th edition, International Hydrographic Bureau, Monaco, Special Publication (44), 2008.

19. C. Parente and M. Pepe. Bathymetry from worldView-3 satellite data using radiometric band ratio, Acta Polytechnica, vol. 58, no. 2, 2018, pp. 109-117. https://doi.org/10.14311/AP.2018.58.0109

20. Y. Yulius, H. L. Salim, and M. Ramdhan. Spatial pattern of bathymetry in Wangi-Wangi Island and its 
surrounding based on GEBCO data and nautical map, Forum Geografi, vol. 29, no. 2, 2016.

https://doi.org/10.2391an, 7/forgeo.v29i2.1113

21. M. F. J. Wilson, B. O'Connel, C. Brown, J. C. Guinan, and A. J. Grehan. Multiscale terrain analysis of multibeam bathymetry data for habitat mapping on the continental slope, Marine Geodesy, vol. 30, no. 1-2, 2007, pp. 3-35. https://doi.org/10.1080/01490410701295962

22. B. Foggi and V. Pancioli. Contributo alla conoscenza della vegetazione dell'Isola del Giglio (Arcipelago Toscano, Toscana meridionale), Webbia, vol. 63, no. 1 , 2008, pp. 25-48. https://doi.org/10.1080/00837792.2008.10670831

23. L. Peruzzi, A. Carta, G. Gestri, G., and B. Pierini. Aggiornamenti e novità sulla distribuzione del genere Gagea (Liliaceae) in Toscana, Atti Società toscana di Scienze naturali, vol. 115, 2008, pp. 95-98.

24. L. Cutroneo, G. Ferretti, D. Scafidi, G. D. Ardizzone, G. Vagge, and M. Capello. Current observations from a looking down vertical V-ADCP: interaction with winds and tide? The case of Giglio Island (Tyrrhenian Sea, Italy), Oceanologia, vol. 59, no. 2, 2017, pp. $139-152$. https://doi.org/10.1016/j.oceano.2016.11.001

25. F. J. Aguilar, F. Agüera, M. A. Aguilar, and F. Carvajal. Effects of terrain morphology, sampling density, and interpolation methods on grid DEM accuracy, Photogrammetric Engineering \& Remote Sensing, vol. 71, no. 7, 2005, pp. 805-816. https://doi.org/10.14358/PERS.71.7.805

26. H. Apaydin, F. Kemal Sonmez, and Y. Ersoy Yildirim. Spatial interpolation techniques for climate data in the GAP region in Turkey, Climate Research,vol. 28, no. 1, 2004, pp. 31-40. https://doi.org/10.3354/cr028031

27. W. Luo, M. C. Taylor, and S. R. Parker. A comparison of spatial interpolation methods to estimate continuous wind speed surfaces using irregularly distributed data from England and Wales, International Journal of Climatology: A Journal of the Royal Meteorological Society, vol. 28, no. 7, 2008, pp. 947-959. https://doi.org/10.1002/joc. 1583

28. M. J. De Smith, M. F. Goodchild, and P. A. Longley. Geospatial analysis: a comprehensive guide to principles, techniques and software tools, Troubador publishing ltd, Leichester (UK), 2007.

29. G. Wang, N. Alamas, and M. Anggraeni. The Use of Internet of Things and Big Data to Improve Customer Data in Insurance Company, International Journal of Emerging Trends in Engineering Research, Vol. 7, no. 12, December 2019, pp. 76-771.

30. A. Dhankhar and K. Solanki. A Comprehensive Review of Tools \& Techniques for Big Data Analytics, International Journal of Emerging Trends in Engineering Research, Volume 7, no. 11, November 2019, pp. 556-562.

31. H. Daltrophe, S. Dolev, and Z. Lotker. Big data interpolation using functional representation, Acta
Informatica, Vol. 55, 2018, pp. 213-225. https://doi.org/10.1007/s00236-016-0288-8

32. M. A. Oliver and R. Webster, Kriging: a method of interpolation for geographical information systems, International Journal of Geographical Information Systems, vol. 4, no. 3, 1990, pp. 313-332.

33. C. A. Rishikeshan, S. K. Katiyar, and V.N. Vishnu Mahesh. Detailed evaluation of DEM interpolation methods in GIS using DGPS data, in International Conference on Computational Intelligence and Communication Networks - 2014, IEEE, 2014.

34. Q. Tan and $\mathrm{X}$. Xu. Comparative analysis of spatial interpolation methods: an experimental study, Sensors \& Transducers, vol. 165, no. 2, 2014, pp. 155.

35. ESRI, Geostatistical Analyst, ArcGIS 10.3- Help, ESRI, Redlands, CA, USA

https://desktop.arcgis.com/en/arcmap/latest/extensions/g eostatistical-analyst/what-is-arcgis-geostatistical-analyst .- htm

36. ESRI, Search neighborhoods, in ArcGIS 10.3- Help, ESRI, Redlands, CA, USA.

37. F. Fathian et al., Temporal trends in precipitation using spatial techniques in GIS over Urmia Lake Basin, Iran, International Journal of Hydrology Science and Technology, vol. 6, 2016, pp. 62-81.

38. U. Falchi, C. Parente, and G. Prezioso. Global geoid adjustment on local area for GIS applications using GNSS permanent station coordinates, Geodesy and Cartography, vol. 44, no. 3, 2018, pp. 80-88. https://doi.org/10.3846/gac.2018.4356

39. D.A Anggoro and W. Supriyanti. Improving accuracy by applying $Z$-score normalization in linear regression and polynomial regression model for real estate data, International Journal of Emerging Trends in Engineering Research, Vol. 7, no. 11, November 2019, pp. 549-555.

40. ESRI, Arc Scene, ArcGIS 10.3-Help, ESRI, Redlands, CA,

USAhttps://desktop.arcgis.com/en/arcmap/10.3/guide-bo oks/extensions/3d-analyst/3d-analyst-and-arcscene.htm 